\title{
Analysis of Potential Tourists' Behaviour in the Process of Deciding Upon a Tourist Destination Based on a Survey Conducted in Bačka Region
}

\begin{abstract}
Lukrecija Djeri', Jovan Plavša, Slobodan Čerović ${ }^{2}$
\end{abstract}

\begin{abstract}
The research into the behaviour of potential tourists regarding the choice of a tourist destination conducted in Backa was done by a survey composed of the analysis of basic indicators, as well as factor analysis. The target segment on the tourist market was the total number of the inhabitants in Backa region, and the sample that represents the target segment was the people of Backa who use the services of chosen travel agents in Novi Sad, Subotica, Sombor, Backa Topola, and Vrbas. The questionnaires reflect the attitude of potential tourists to the decision-making process regarding the choice of a tourist destination. The selection of the sample was done randomly and was limited to the number of people who visited those travel agents' and their willingness to do the questionnaire.
\end{abstract}

Key words: tourists' behaviour, tourist destination selection, Bačka

\footnotetext{
Provincial Secretariat for Education and Culture, Bulevar Mihajla Pupina 16, 21000 Novi Sad, Serbia.

2 Department of Geography, Tourism and Hotel Management, Faculty of Sciences, University of Novi Sad, Trg Dositeja Obradovića 3, 21000 Novi Sad, Serbia
}

\section{Introduction}

The main goal of all marketing activities of a travel company is satisfying the needs and wishes of potential tourists in the way that ensures increased sales and profit in the long run. Business results of a travel company depend largely on the satisfaction of customers. Returning costumers as well as established relationship of loyalty are sings that the company is doing well on the tourist market. Successful marketing strategies based on the knowledge of potential tourists' needs and wishes determine sales and profit of a particular travel company. Expected sales and profit are influenced by the level of satisfaction of customers, i.e. tourists who trust a particular travel company.

The knowledge of the needs and wishes of potential tourists is an essential input for a travel company to make marketingrelated decisions. Information on potential tourists' behaviour in different situations concerning the choice of tourist destination creates a solid basis for planning marketing strategies, such as differentiation of tourist products and service, positioning or re-positioning of tourist products and services, segmentation of the tourist market, etc.

The more pieces of relevant information on customers and services on the tourist market, the better marketing activities aimed at driving potential customers' behaviour. The knowledge of customers is a good basis for making marketing decisions unless the reality requires new additional information. Anyhow, marketing research into the potential customers' behaviour is irreplaceable and invaluable.

Marketing research into the behavior of potential tourists in the process of making a decision about a tourist destination uses the results of research carried out in many specialized disciplines, such as geography, sociology, psychology, anthropology, eco- nomics, etc. which deal with particular modes of potential tourists' behaviour so as to make it possible to understand those different modes, as well as to ensure satisfying tourists' needs and achieving business success. Potential tourists' behavior is primarily determined as micromarketing research.

\section{The Process of Making Decision About a Tourist Destination}

One of the most important segments of research regarding customers' behaviour in tourism is the process of making a decision about a tourist destination. That choice is, in fact, potential tourists' response to a particular problem. The decision-making presupposes making a choice between two, or more than two, options, i.e. modes of behaviour. Potential tourists are always in a position to make choices, i.e. to choose between two or more alternatives. The choice itself represents a desire to satisfy certain needs and wishes by choosing a particular tourist destination. However, to be able to make rational decisions, potential tourists need adequate information. By choosing a particular tourist destination, potential customers decide on the allocation of available financial resources, on the travel agent's, etc. There is a wide array of different modes of bahaviour on behalf of potential tourists when it comes to making a decision about a tourist destination. The analysis of the decision-making involves research into how they choose among different tourist destination offers, as well as processes that precede and are a part of the decision-making itself. Research is done also after the purchase, i.e. after tourists' return from a chosen destination. In general, the decision-making is composed of two segments: the process itself and the factors that affect the process. The decision-making involves affective and cognitive behaviour (Schiffman, Kanuk, 200o). 


\section{Decision - Making Phases}

There are four ways to identify basic phases concerning making a decision about a tourist destination. The first, or introspective, way presupposes generalization based on the analysis of tourists' own behaviour and is limited in scope. The second, retrospective, method applies surveying a small group of potential tourists so as to determine the factors that affected their choice. The third, prospective, way involves finding a relevant potential tourist who would explain how he made a decision. The fourth, prescriptive, method is based on asking a small group of people to describe an ideal way of successful decision-making regarding the choice of a tourist destination. This method is considered to be rational since it presupposes that a potential tourist uses certain rules that help him choose the best alternative, i.e. tourist destination.

The most commonly analyzed is the classical decision-making model which treats a potential tourist as a person who, by making a decision about a tourist destination, solves his problem, and it involves five phases:

- need awareness,

- search for information,

- estimation of alternatives,

- decision about purchasing a tourist product or service,

- feedback after purchasing (Graph 1).

Decision making process commences when a potential tourist becomes aware of a certain need (need for buying, change of the environment, or various forms of entertainment, etc.) If the need is strong enough or it has been transformed into a desire, a potential tourist is motivated to start the search for information on tourist destination offers where he/she can satisfy his/her need. Predominantly, the search for information is caused by the level of engagement of a potential tourist in choosing the tourist destination and the process of obtaining information. In the next phase, a potential tourist can estimate alternatives and criteria for choosing the most favourable destination, on the basis of available information. During this phase, the attitudes on different types of offers within tourist destinations are predominant. During the fourth phase, a potential tourist reaches he final decision, i.e. by choosing one of the available alternatives, and turns into a real consumer in tourism sector. In fact, a potential tourist buys an actual package or partial tourist products and services in the selected destination. The process of decision making ends with the evaluation of the purchase, most frequently on the basis of the level of satisfaction reached after returning from the selected tourist destination, i.e. consuming the selected tourist

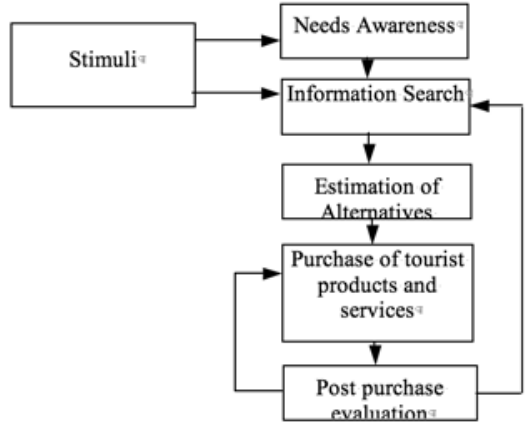

Graph 1 Decision making process of potential tourists (Maričić, 2002)

product or service. Practically, the level of satisfaction with the selected tourist destination is the key factor upon which the next selection of the tourist destination is made, as well as the travel agent is chosen.

The level of involvedness, i.e. interestedness of potential tourists within the decision making process in tourist destination selection is the indicator of the importance of the option and activities in problem solving and motivation potential during certain phases of the process of decision making and purchase (Table 1).

The main point of the analysis is to indicate that decision making process in tourist destination selection is a complex process which potential tourists pass through to reach their final decisions. Primarily, it refers to the decisions demanding a high level of involvement of potential tourists, but also in numerous cases, it is applicable to the so called routine type of decision making. The act of selection and purchase is observed as one of the phases in that process. However, it is significant to highlight that the process of decision making starts much earlier than the actual purchase and that it also involves the post purchase evaluation, i.e. the satisfaction level of the consumer of tourist product or services in a tourist destination. Moreover, there are situations when a potential tour- ist does not have to traverse all the phases in decision making process. Such is the case of highly conscious tourists, who are well informed and have already acquired high level of tourist culture, i.e. the culture of travelling (Pavluska - www.gaia.

\section{Research on Behaviour of Potential Tourists When Selecting a Tourist Destination - Case Study of Bačka}

The research on behaviour of potential tourists when selecting a tourist destination - case study of Bačka has been conducted through a questionnaire, which infactor analysis.

The first part of the questionnaire consisted of ten basic indicators intended to divide the informants according to different criteria. The potential tourists - the informants were divided by the place of residence, gender and age structure, level of education attained, employment type, type of household, the number of family members and monthly income within a household.

The second part of the questionnaire consisted of questions referring to all five phases in the decision making process when selecting a tourist destination. The number of questions differs according to the features of the phases they refer to.

Among the basic indicators there are the most prominent four (place of residence, age structure, level of education attained, monthly family income) which have contributed to the estimation of the frequency variation according to phases of decision making process in tourist destination selection. Other six criteria of the first par of the questionnaire have been analyzed according to the answers of 252 informants, jpte.hu) cluded the analysis of basic indicators and professional qualifications, marital status,

Table 1 The level of involvedness of a potential tourist in the decision making process when selecting a tourist destination

\begin{tabular}{|l|l|l|}
\hline & HIGH INVOLVEDNESS & LOW INVOLVEDNESS \\
\hline $\begin{array}{l}\text { Awareness of needs and } \\
\text { problems }\end{array}$ & Significant & Insignificant i.e. minimal \\
\hline Information search & Active and broad & $\begin{array}{l}\text { Passive, within the } \\
\text { predetermined scope }\end{array}$ \\
\hline Information base & $\begin{array}{l}\text { Broad with numerous } \\
\text { criteria }\end{array}$ & Narrow with several criteria \\
\hline Estimation of alternatives & Profound & Superficial \\
\hline Decision making alternative & $\begin{array}{l}\text { Small number of } \\
\text { alternatives }\end{array}$ & $\begin{array}{l}\text { Large number of } \\
\text { alternatives }\end{array}$ \\
\hline Social influence & Large, extreme influence & Moderate social influence \\
\hline $\begin{array}{l}\text { Faithfulness to the tourist } \\
\text { product, brand }\end{array}$ & Strong and decisive & Unsatisfactory \\
\hline Post purchase estimation & Profound & Limited \\
\hline
\end{tabular}

Source: Pavluska,.V. - www.gaia.jpte.hu/hallgatok/levelezo/Fogymag_files/slideooo1.htm 
Table 2 The forms of recognizing the need for traveling

\begin{tabular}{|l|c|c|c|c|c|}
\hline & Routine & Planned & Social influence & Family consent & Other \\
\hline $\mathrm{n}$ & 19 & 85 & 43 & 104 & 1 \\
\hline$\%$ & 7.54 & 33.73 & 17.06 & 41.27 & 0.40 \\
\hline
\end{tabular}

Data obtained in a questionnaire

but lacking the estimation of frequency variation within different phases.

The basic span of the research, i.e. the target segment of the research was the population of Bačka, and the sample which represents the basic span consists of the individuals who consume the services of selected travel agents in Novi Sad, Subotica, Sombor, Bačka Topola and Vrbas. The questionnaires reflect the opinion of potential tourists upon the process of decision making when selecting a tourist destination.

The sample has been selected at random and limited by visits to travel agents and their free will to participate in questionnaire. Univariate and multivariate methods have been used in the mathematical-statistical procedure of data processing: multivariate analysis (MANOVA), discriminative analysis, Roy's test, coefficient of discrimination, Pearson's coefficient of contingency $(c)$, coefficient of multiple coleration $(\mathrm{P})$, and Fisher's test (F) (Hadžić, 1989).

Application of methods on the basis of which the measure has been obtained throws new light to the research. The features defining specificity of groups and also those to be excluded from further research have been revealed by calculating the discrimination coefficient.

Significant differences between the groups are highlighted by the value "p", i.e. the risk of concluding. For the value of is p> 0.1, there is no difference between the observed groups (place of residence, age structure, level of education attained, etc.). But for $0.1>p>0.05$, there is a slight difference with the increased risk of concluding, and for $\mathrm{p}>0.05$ there is a significant variation between the observed groups.

\section{Analysis of Basic Indicators Through Phases Factor Analysis by Age Structure}

This part of the research concentrates on the analysis according to the phases in the process of decision making of potential tourists when selecting a tourist destination.

\section{Analysis of the informants answers to the first phase set of questions - awareness of needs \\ Most frequently potential tourists recognize their needs for travelling through the fami- ly consent (104 informants or $41.27 \%$ ). Then follows the group with planned reactions, considering all options $(33.73 \%, \mathrm{p}=0.081)$.}

In the third place comes the group of those who have immediate reactions influ-

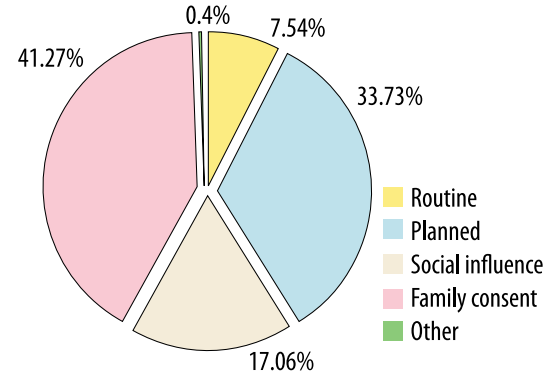

Graph 2 Recognition of needs for travelling (\%). Representation of geographical factors at decision making process about travelling

enced by the social environment $(17.06 \%, \mathrm{p}=$ $0.000)$, then follows the group of those who reach the decision routinely $(7.54 \% \mathrm{p}=0.000)$, whereas there is the insignificant number of those who reach the decision in other ways (0.40\% p= 0.00o) (Table 2, Graph 2).

\section{Analysis of the informants answers to the second phase set of questions - information search}

The research has shown that personal sources stand for the most trustworthy sources of information on tourist destination (46.83\%), then follows the group of informants who reach their decision on the basis of opinions of their family and friends (35.71\%, $\mathrm{p}=0.012$ ). destination (inf 3)

Data obtained in a questionnaire destination (\%)
Further analysis indicates that the third important place is occupied by marketing sources $(11.90 \%, \mathrm{p}=0.000)$, then follows the group of informants who reach their decisions on the basis of neutral sources, such as $\mathrm{NGO}$, organizations for consumer protection, etc. $(4.7 \%, \mathrm{p}=0.00)$ (Table 3, Graph 3).

\section{Analysis of the informants answers to the third phase set of questions - estimation of alternatives}

Almost 50\% (46.4\%) of potential tourists reach their final decision in the process of tourist destination selection through a mutual consent with family and friends, which highlights the still prominent feature of patriarchal family and the fact that very important decisions are not reached fast and independently.

Large number of informants (almost $40 \%$, i.e. $38.49 \%, p=0.072$ ) reach their decision relatively easy and relying on own intuition, whereas only $15.08 \%(\mathrm{p}=0.000)$ of the informants reach their decision rather hard and after a lot of estimation of existing alternatives (Graph 4).

\section{Analysis of the informants answers to the fourth phase set of questions - purchase}

When the final decision on purchasing a tourist product is being reached, numerous factors need to be taken into account, related people are being consulted, but the final decision is reached on the basis of personal estimation according to the almost one third of informants (63.5\%).

Right after the leading factor, the next factor of influence in purchasing the tourist product is the influence of unpredicted situ-

Table 3 Representation of the most trustworthy sources of information on tourist

\begin{tabular}{|l|c|c|c|c|c|}
\hline & $\begin{array}{c}\text { Marketing } \\
\text { sources }\end{array}$ & $\begin{array}{c}\text { Personal } \\
\text { sources }\end{array}$ & $\begin{array}{c}\text { Family and } \\
\text { friends' opinion }\end{array}$ & $\begin{array}{c}\text { Neutral } \\
\text { sources }\end{array}$ & No answer \\
\hline $\mathrm{n}$ & 30 & 118 & 90 & 11 & 3 \\
\hline$\%$ & 11.90 & 46.83 & 35.71 & 4.37 & 1.19 \\
\hline
\end{tabular}

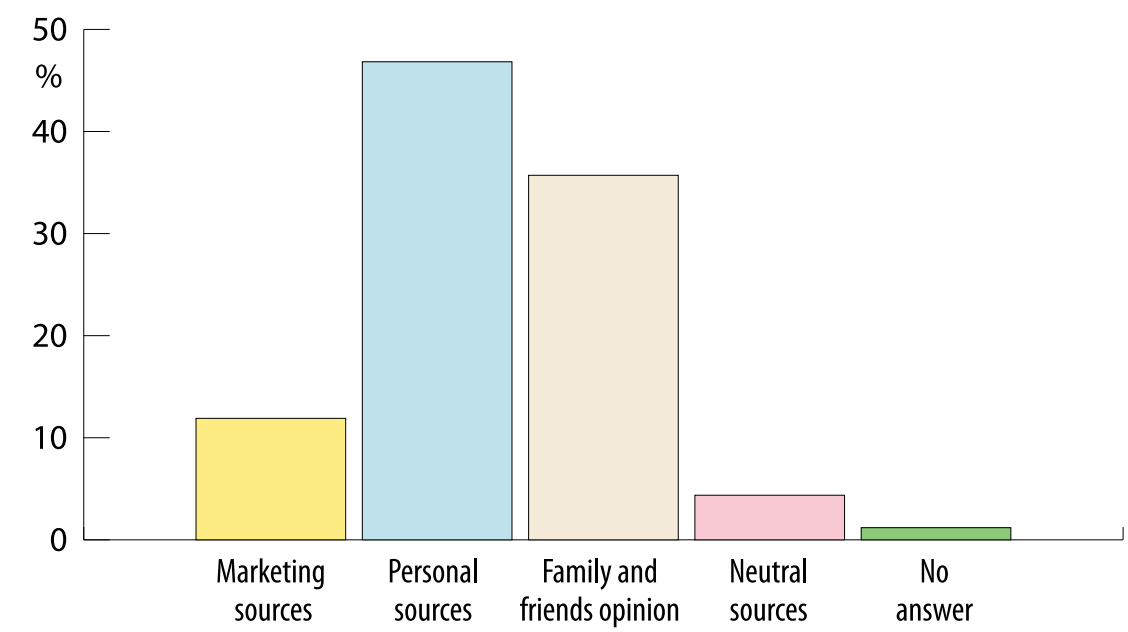

Graph 3 Representation of the most trustworthy sources of information on a tourist 


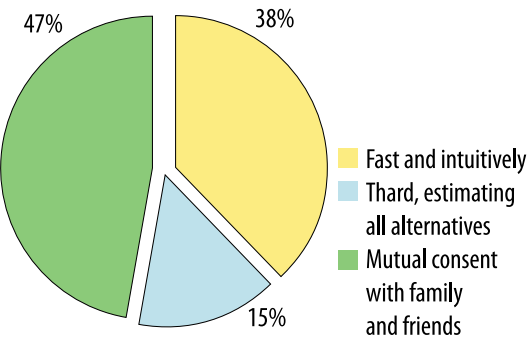

Graph 4 The forms of decision making in the process of tourist destination selection, in percentages (\%)

ations $(16.3 \%, \mathrm{p}=0.000)$ and mainly sudden and instable situations - natural disasters, political and economic instability, terrorist acts, etc. $(12.30 \%, \mathrm{p}=0.000)($ Table 5 , Graph 5).

\section{Analysis of the informants answers to the fifth phase set of questions - repeated purchase}

It is widely known that the best advertisement in tourism is tourist satisfaction, i.e. it may be assumed that the tourist will more easily repeat the purchase with the same travel agent if he/she was satisfied with the previous package. This statement is supported by the results of our research, where the decision of over $40 \%$ informants is significantly influenced by their previous travels with the same travel agent.

For $26.6 \%(p=0.001)$ informants the earlier travels have important influence on making the decision where to travel again, i.e. which package to accept. It means that for two thirds of informants $(40.9 \%$ plus

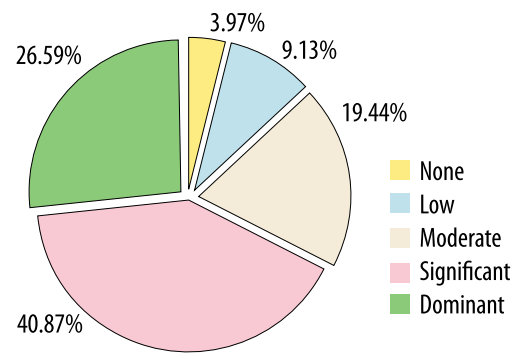

Graph 6 Influence of satisfaction on repeated purchase at the same travel agent, in percentages (\%)

26.6\%) the previous travels are crucial in decision making process when selecting a new destination. Only one third of potential tourists is less influenced by their earlier travel packages (Table 6, Graph 6).

\section{Factor Analysis in Relation} to Age Structure

\section{Analysis of the first phase variations - needs awareness in relation to age structure}

According to the fact that $\mathrm{p}=0.000$ (Table 7) in MANOVA, it is evident that there is a significant variation between the answers of potential tourists to the set of questions in the first phase of the decision making

Table 4 The forms of decision making in the process of tourist destination selection (pal1)

\begin{tabular}{|l|c|c|c|}
\hline & $\begin{array}{c}\text { Fast and } \\
\text { intuitively }\end{array}$ & $\begin{array}{c}\text { Hard, estimating all } \\
\text { alternatives }\end{array}$ & $\begin{array}{c}\text { Through mutual consent } \\
\text { with family and friends }\end{array}$ \\
\hline $\mathrm{n}$ & 97 & 38 & 117 \\
\hline$\%$ & 38.49 & 15.08 & 46.43 \\
\hline
\end{tabular}

Data obtained in a questionnaire

Table 5 Factors of influence in decision making in purchasing the tourist product (kup1)

\begin{tabular}{|l|c|c|c|c|c|c|c|c|}
\hline & $\begin{array}{c}\text { No } \\
\text { answer }\end{array}$ & $\begin{array}{c}\text { Personal } \\
\text { estimation }\end{array}$ & $\begin{array}{c}\text { Preferred } \\
\text { product }\end{array}$ & $\begin{array}{c}\text { Attitudes } \\
\text { of others }\end{array}$ & $\begin{array}{c}\text { Unpredictable } \\
\text { situations }\end{array}$ & $\begin{array}{c}\text { a) Inflation } \\
\text { and } \\
\text { additional } \\
\text { payments }\end{array}$ & $\begin{array}{c}\text { b) Instable } \\
\text { situation }\end{array}$ & c)0ther \\
\hline $\mathrm{n}$ & 1 & 160 & 35 & 15 & 41 & 7 & 31 & 3 \\
\hline$\%$ & 0.40 & 63.49 & 13.89 & 5.95 & 16.27 & 2.78 & 12.30 & 1.19 \\
\hline
\end{tabular}

Data obtained through questionnaire research

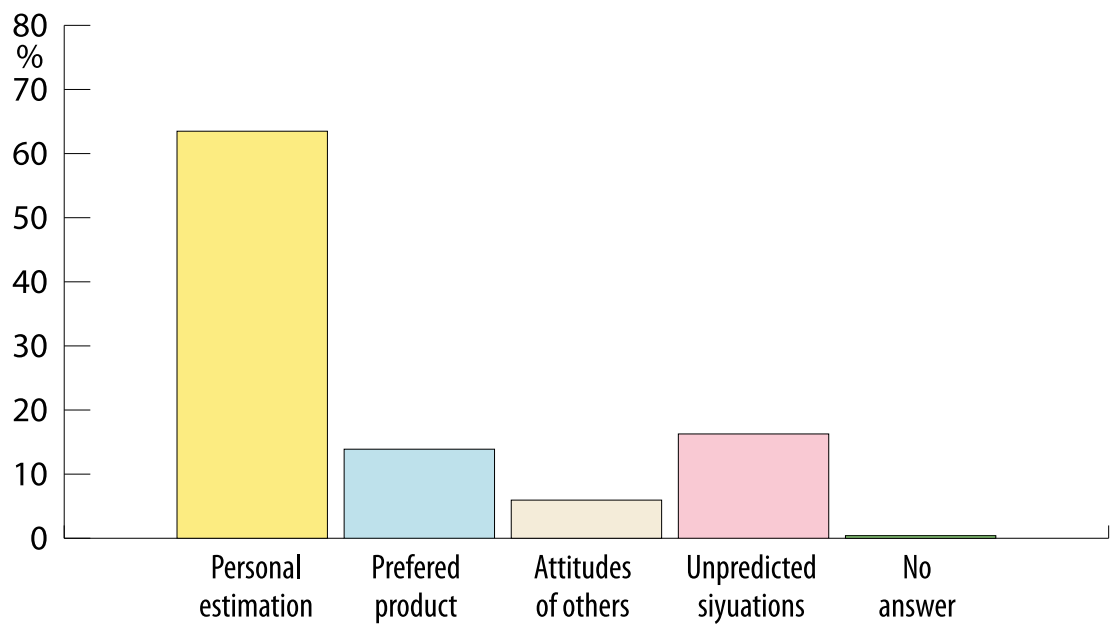

Graph 5 Factors of influence in decision making when purchasing a tourist product, in percentages (\%)

Table 6 Influence of satisfaction on repeated purchase with the same travel agent (oku1)

\begin{tabular}{|l|c|c|c|c|c|}
\hline & $\begin{array}{c}\text { Without } \\
\text { influence }\end{array}$ & $\begin{array}{c}\text { Low } \\
\text { influence }\end{array}$ & $\begin{array}{c}\text { Moderate } \\
\text { influence }\end{array}$ & $\begin{array}{c}\text { Significant } \\
\text { influence }\end{array}$ & $\begin{array}{c}\text { Dominant } \\
\text { influence }\end{array}$ \\
\hline $\mathrm{n}$ & 10 & 23 & 49 & 103 & 67 \\
\hline$\%$ & 3.97 & 9.13 & 19.44 & 40.87 & 26.59 \\
\hline
\end{tabular}

Data obtained through questionnaire research

process when selecting a tourist destination in relation to age structure of the informants.

The analysis of discrimination coef ficient (Table 8) has shown that it is the highest with the representation of need which potential tourists would first satisfy if they had unrestricted funds at their disposal (prio) (o.119), then with representation of social factors at making the final decision about the travelling (soci) (o.082) and finally the way of spending free time (vrem) (o.075).

Table 7 Significant variations in the first phase compared to age structure of potential tourists

\begin{tabular}{|l|c|c|c|}
\hline & $\mathbf{n}$ & $\mathbf{f}$ & $\mathbf{p}$ \\
\hline Manova* $^{*}$ & 10 & 3.856 & 0.000 \\
\hline
\end{tabular}

Data obtained through questionnaire analysis
Analysis of the second phase variations - information search in relation to age structure of potential tourists

According to MANOVA where $p=0.000$ (Table 9, ) this phase also highlights a significant variation in potential tourists' answers to the set of question in the second phase in the process of decision making when selecting a tourist destination in relation to age structure of informants, although the variation is less prominent compared to the first phase.

The analysis of discrimination coefficient (Table 10) has shown its highest values at three different points: first the influence of urgent selection and reaching the decision on travelling to the intensity of collecting information about travelling (inf9) (o.098), second the influence of discounts to the intensity of collecting information about a tourist destination (inf8) (o.o89) and finally the type of marketing 
Table 8 Coefficient of discrimination in the firs phase compared to age structure of potential tourists

\begin{tabular}{|l|c|}
\hline & Discrimination coefficient \\
\hline prio $^{1}$ & 0.119 \\
\hline soci & 0.082 \\
\hline vrem & 0.075 \\
\hline psih & 0.071 \\
\hline geog & 0.064 \\
\hline vrtr & 0.062 \\
\hline ekn2 & 0.052 \\
\hline put2 & 0.048 \\
\hline put1 & 0.046 \\
\hline ekn1 & 0.036 \\
\hline
\end{tabular}

Data obtained through questionnaire analysis

'The first three parameters with the highest discrimination coefficient in Table 8: prio - representation of needs that potential tourists would first satisfy if they had unrestricted funds available, soci-representation of social factors in the decision making process about travelling, vrem - the ways of spending free time.

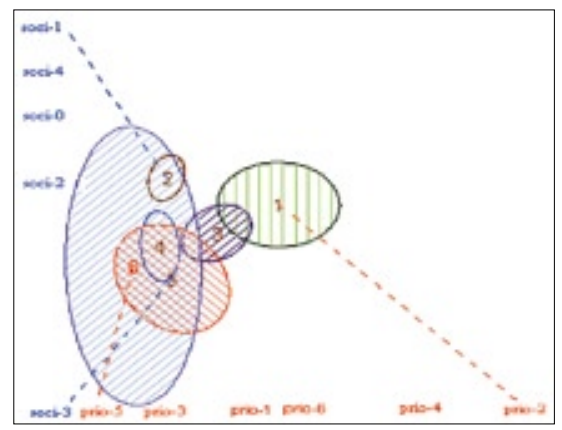

Graph 7 Representation of needs which potential tourists would satisfy first, implying they had available unlimited financial resources and social factors at decision making process in travelling compared to the answers scale. Legend: 18-25 age group (1); 26-35 age group (2); 6-45 age group (3); 46-55 age group (4); 56-65 age group (5); 66 + age group (6); Need for travelling (prio-1); Need for self-esteem (prio-2); Need for belonging (prio-3); Status (prio-4); Need for safety and security (prio-5); Physiological needs (prio-6); No ansswer (soci-o); Habits, expectations (soci-1); Life style (soci-2); Family, friends (soci-3); Market trends (soci-4).

Table 9 Significance of the second phase compared to age structure of potential tourists

\begin{tabular}{|l|c|c|c|}
\hline & $\mathbf{n}$ & $\mathbf{f}$ & $\mathbf{p}$ \\
\hline Manova* $^{*}$ & 11 & 2.717 & 0.000 \\
\hline
\end{tabular}

Data obtained through questionnaire analysis

sources with the highest influence in the information search process (inf4) (0.072).

\section{Analysis of the third phase variations - estimation of alternatives in relation to age structure}

In this phase MANOVA also indicates that there is a significant variation between the
Table 10 Discrimination coefficient in the second phase compared to age structure of potential tourists

\begin{tabular}{|l|c|}
\hline & Discrimination coefficient \\
\hline inf9 $^{1}$ & 0.098 \\
\hline inf8 & 0.089 \\
\hline inf4 & 0.072 \\
\hline inf1 & 0.071 \\
\hline inf5 & 0.068 \\
\hline inf7 & 0.048 \\
\hline inf3 & 0.034 \\
\hline inf2 & 0.033 \\
\hline inf6 & 0.030 \\
\hline inf6 & 0.029 \\
\hline infa & 0.024 \\
\hline
\end{tabular}

Data obtained through questionnaire analysis

'The first three parameters with the highest discrimination coefficient in Table 10: info - the influence of urgent decision making about travelling to the intensity of information search about travelling, infs - the influence of discount offers to the intensity of information search about a tourist destination, inf4- the types of marketing sources of highest influence in the process of information search.

answers of potential tourists to the set of questions in the third phase in the decision making process when selecting a tourist destination in relation to age structure of the informants (Table 11). This variation is more prominent in comparison to the previous and the next phases of this analysis.

The analysis of discrimination coefficient (Table 12) has shown that it is the most prominent with the most significant factors in alternatives estimation of tourist destinations (pa21) (o.127) and the ways of decision making when selecting a tourist destination (pal1) (o.039).

Table 11 Significance of variations in the third phase in relation to age structure of potential tourists

\begin{tabular}{|l|c|c|c|}
\hline & $\mathbf{n}$ & $\mathbf{f}$ & $\mathbf{p}$ \\
\hline Manova* $^{*}$ & 3 & 4.390 & 0.000 \\
\hline
\end{tabular}

Data obtained through questionnaire analysis

Table 12 Discrimination coefficient in the third phase in relation to age structure of potential tourists

\begin{tabular}{|l|c|}
\hline & Discrimination coefficient \\
\hline pa21 $^{1}$ & 0.127 \\
\hline pal1 $^{1}$ & 0.039 \\
\hline
\end{tabular}

Data obtained through questionnaire analysis

'Parametres with the highest discrimination coefficient in Table 12: pa21 - the most significant factors in alternatives estimation of tourist destinations, pal1 - the way of reaching the final decision when selecting a tourist destination.

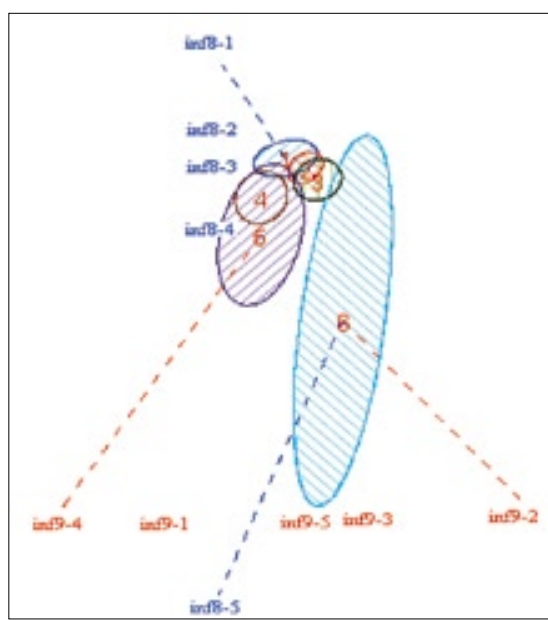

Graph $\mathbf{8}$ Influence of urgent selection in decision making process about the travelling on the intensity of information collecting on travelling and influence of discounts on the intensity of information collecting on tourist destination in relation to the answers' scale Legend: 18-25 age group (1); 26-35 age group (2); 36-45 age group (3); 46-55 age group (4); 56-65 age group (5); 66+ age group (6); None (inf9-1); Low (infg-2); Moderatee (inf9-3); Significant influence (inf9-4); Dominant influence (inf9-5); None (inf8-1); Low (inf8-2); Moderate (inf8-3); Significant influence (inf8-4); Dominant influence (inf8-5).

\section{Analysis of the fourth phase variations - purchase of tourist product in relation to age structure}

Furthermore, MANOVA implies that there are significant variations between the answers of potential tourists to the set of questions in the fourth phase in the deci-

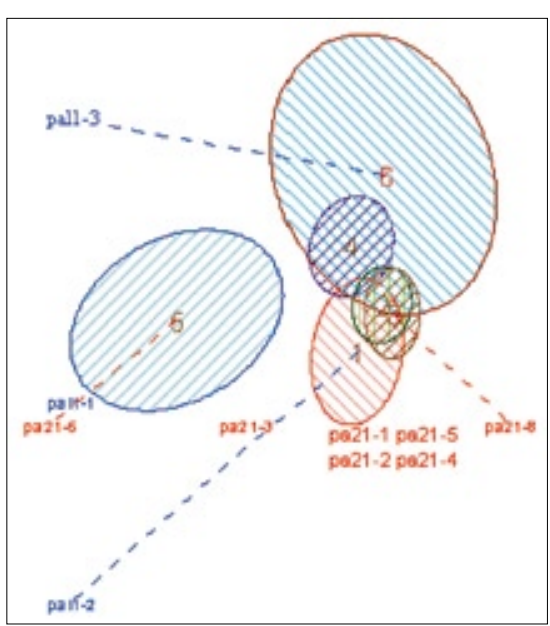

Graph 9 Crucial factors in estimation of alternatives of tourist destinations and ways of decision making when selecting a tourist destination

Legend: 18 -25 age group (1); 26-35 age group (2); 36-45 age group (3); 46-55 age group (4); 56-65 age group (5); 66 + age group (6); Quality, style, prestige (pa21-1); Preferences, expectations, atitudes (pa21-2); Kindly atmosphere at the selling point (pa21-3); Life style, opinions of others (pa21-4); Prices, payment options (pa21-5); Experineces (pa21-6); All inclusive packages (pa21-8); Fast and intuitively (pal1-1); Hard, estimating all alternatives (pal1-2); By mutual consent with family and friends (pal1-3). 
sion making process when selecting a tourist destination in relation to age structure, however, this variation is almost twice less prominent than in the previous phase.

The analysis of discrimination coefficient (Table 14) has shown its highest value at: the factor of influence upon deciding on the purchase of a particular tourist product (kup1) (0.130), influence of unpredicted situations at the selling point on reaching the final decision (kup6) (o.082) and

Table 13 Significance of the fourth phase variations In relation to the age structure of potential tourists

\begin{tabular}{|l|c|c|c|}
\hline & $\mathbf{n}$ & $\mathbf{f}$ & $\mathbf{p}$ \\
\hline Manova* & 6 & 2.818 & 0.000 \\
\hline
\end{tabular}

Data obtained through questionnaire analysis

Table 14 Discrimination coefficient in the fourth phase in relation to the age structure of potential tourists

\begin{tabular}{|l|c|}
\hline & Discrimination coefficient \\
\hline kup1 & 0.130 \\
\hline kup6 & 0.082 \\
\hline kup2 & 0.078 \\
\hline kup4 & 0.059 \\
\hline kup3 & 0.016 \\
\hline kup5 & 0.011 \\
\hline
\end{tabular}

Data obtained through questionnaire analysis

${ }^{1} T$ The first three parameters with the highest discrimination coefficient in Table 14: kup1 - factors of influence in the decision making process when purchasing the tourist product, kup6 - the influence of unpredicted situations at the selling point to reaching the final decision, kup2 - the selling point of tourist packages.

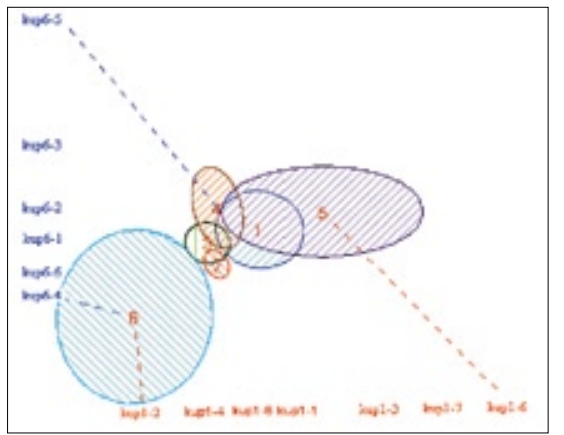

Graph 10 Factors of influence in decision making when purchasing tourist products and the influence of unpredicted situations at the selling point on reaching the final decision in relation to the answers' scale.

Legend: 18-25 age group (1); 26-35 age group (2); 36-45 age group (3); 46-55 age group (4); 56-65 age group (5); $66+$ age group (6); No answer (kup1-0); Personal estimation (kup1-1); Preferred product (kup1-2); Attitudes o fothers (kup1-3); Unpredicted situations (kup1-4); Inflation and additional payments (kup1-5); Instable situation (kup1-6); Other (kup1-7); Impolite personnel (kup6-1); Physical environment (kup6-2); Impulsive purchase (kup6-3); Psychological temper (kup6-4); Time of purchase (kup6-5); the selling point of tourist packages (kup2) (o.087).

\section{Analysis of the fifth phase - post purchase evaluation in relation to age structure}

Furthermore, significant variations be tween the answers of potential tourists have been registered in the fifth phase in the decision making process when selecting a tourist destination in relation to age structure. The variations tend to be more prominent than in the fourth phase, but less prominent than in the third phase.

Discrimination coefficient (Table 16) is the highest with the preferred forms of tourism (oku5) (o.154), whereas it is slightly lower with the reasons for making decisions about tourist travels (oku4) (o.118) and the frequency of tourist travels (oku2) (o.108).

\section{Concluding Remarks}

During the research of the behaviour of potential tourists when selecting a tourist destination - case study of Bačka, out of the basic indicators (the total of ten indicated in this paper), four have been selected: place of residence, age structure, level of education attained, and monthly family income, to establish the characteristics of the decision making process.

By means of the data analysis obtained through the questionnaire, efforts have been made to identify mutual features of various structures of informants which would be distinctive for their behaviour in the decision making process when selecting a tourist destination.

This paper presents the main features of the decision making process of potential tourists when selecting a tourist destination according to phases and compared to age structure of informants. Generally, we may conclude that there are very few common features, i.e. the informants' answers reveal outsized divergences compared to various age groups.

One of the common features among majority of informants in different age groups is the answer to the question about the most frequent reasons for travelling. Informants in all age groups, except for the last one $66+$ answered that it is the desire to leave the familiar environment for at least a short period of time and visit new places, meet new people and their customs.

The next common feature refers to psychological factors influencing the decisions about travelling. Informants in all age groups, except for the last one $66+$, responded that they travel for the pleasure that travelling may offer.

Four last age groups of informants agree upon the statement that they become aware of the need for travelling only after they have talked and agreed with their family.
Table 15 Significance of the fifth phase variations in relation to the age structure of potential tourists

\begin{tabular}{|l|c|c|c|}
\hline & $\mathbf{n}$ & $\mathbf{f}$ & $\mathbf{p}$ \\
\hline Manova* $^{*}$ & 10 & 3.546 & 0.000 \\
\hline
\end{tabular}

Data obtained through questionnaire analysis

Table 16 Discrimination coefficient in the fourth phase in relation to the age structure of potential tourists

\begin{tabular}{|l|c|}
\hline & Discrimination coefficient \\
\hline oku5 $^{1}$ & 0.154 \\
\hline Oky4 & 0.118 \\
\hline oku2 & 0.108 \\
\hline oku9 & 0.085 \\
\hline oku1 & 0.070 \\
\hline oku3 & 0.068 \\
\hline oku7 & 0.052 \\
\hline oku6 & 0.036 \\
\hline okua & 0.033 \\
\hline Oku8 & 0.031 \\
\hline
\end{tabular}

Data obtained through questionnaire analysis

${ }^{1}$ The first three parameters with the highest discrimination coefficient in Table16: oku5 - preferred forms of tourism, oku4 - the reasons for selecting tourist travels, oku2 - frequency of tourist travels.

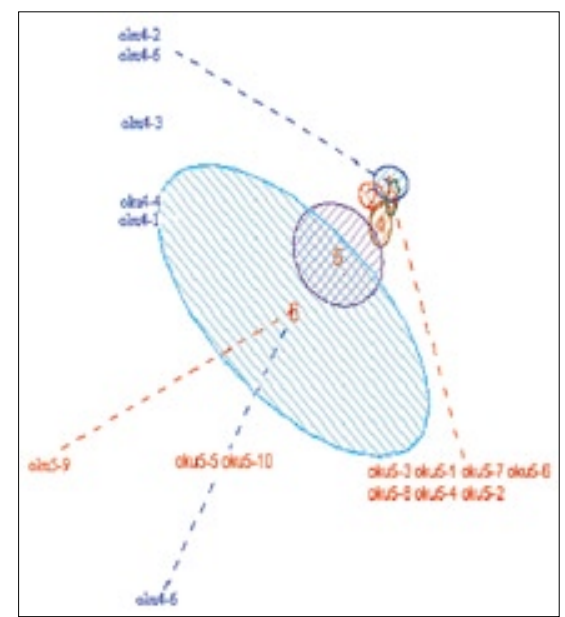

Graph 11 Primary forms of tourism and reasons for travelling in relation to the answers' scale

Legend: 18-25 age group (1); 26-35 age group (2); 36-45 age group (3); 46-55 age group (4); 56-65 age group (5); 66 + age group (6); Summer holidays at the sea (oku5-1): Winter holidays in the mountains (oku5-2); Holidays in ecological environment (oku5-3): Extreme sports (oku5-4); Active holidays in the country (oku5-5); Exotic travels (oku5-6); Cruises (oku5-7); Round trips (oku5-8); Short excursions (oku5-9); Other (oku5-10); Holidays, relaxation, recreation, and pleasure (oku4-1); New experience (oku4-2); Introduction to other cultures (oku4-3); Introduction to natural beauties in other areas (oku4-4); 
A remarkable point is the answer of informants in the 56-65 age group to the question about the priority of needs to be met, quite opposite of the other groups, it was the need for travelling.

At estimation of alternatives, it may be perceived that, among younger population, preferences, expectations and attitudes about tourist offer, the quality of tourist offer, image and prestige of tourist destination are the most important, whereas among middle-aged and older age groups, experiences, politeness and atmosphere in the selling place stand for the most important factors, which is in concordance with the expectations about the members of different age groups.

The only perceived common feature in the fourth phase in the process of decision making when selecting a tourist destination is the fact that the decision upon the purchase of tourist package is influenced by unpredicted situations such as: inflation, possible additional payments, instable situation at the selected tourist destination (natural disasters, economic instability, terrorist acts). Such features are common for all age groups between 26-35 and 56-65.

Interestingly enough, the post purchase evaluation phase has illustrated that it is a common feature for all age groups to travel from time to time, which is probably more the evidence of economic situation in our country than the lack of need for traveling.

For all other questions there is a whole range of answers and significant tangible areas have not been identified among the informants of different age groups.

During the analysis of the research, certain standard procedures in the process of decision making when selecting a tourist destination were recognized:

1. The process of decision making of potential tourists when selecting a tourist destination is influenced by numerous, changeable factors, depending to the influence of tourist needs and habits of the consumers in tourism, as well as of the influence of external economic and non-economic factors.

2. The intensity of the influence and the instant of external factors influence will vary and depend on the level of tourist needs i.e. habits (if a tourist has developed tourist culture, he/she knows exactly which product or service he/she wants, and in that case the influence of those factors to his/her decision is mini- mal in comparison to a tourist with less developed tourist culture).

3. Potential tourists in the process of decision making when purchasing a tourist product do not always pass all phases in that process, also the number of factors of influence and the time span of certain phases varies.

4. The more knowledge about tourist offer or tourist destination increases, the intensity of information search decreases.

5. The satisfaction of tourists with selected tourist product or services greatly influences them to rely to their internal (memorised) information.

6. Faithfulness to a certain brand of tourist product or service reduces the efforts in information search. Furthermore, urgent selection and final decision, together with special discount offers influence the quantity of external information to be obtained.

7. Assuming that potential tourists have unlimited economic sources, the influence of satisfying psychological needs predominates physiological ones. E.g. potential tourists rather decide to travel than to buy a product for personal use.

In the last few years there are new trends in tourist behaviour at the tourist market, which marketing experts in tourism need to concentrate on.

- Potential tourists are more self-conscious and fastidious.

- They are well informed and efficient in decision making process when selecting a tourist destination.

- They are more independent in decision making process when selecting a tourist destination and less frequently fall into stereotypes.

- Dissimilarity between potential tourists is more evident.

- A single tourist features in his/her behaviour when selecting a tourist destination several types of tourists.

- Ecological awareness increases.

- Psychological factors, such as emotion dominate and influence the decisions of potential tourists when selecting a tourist destination

- Tourists form their status symbols, i.e. more frequently travel to famous tourist destinations.

- New types of tourist are being shaped, whose features have not been studied yet (militant, extreme and adrenaline sport fans, eco tourists, etc.)
- Parallel to the main motifs (swimming, relaxation, culture), a new package of motifs for tourist travels emerges: intensive pleasure, activities in nature, prominent need for experience, sensitivity, emotions, recreation and health.

- Mainly tourists seek for quite the opposite of their everyday environment and atmosphere.

- Higher expectations of tourists are supported by mass media and modern technology, higher level of education attained and personal experience and knowledge.

- Innovative offers and stages emerge and provide apart from the standard ones, unusual experience and surprises.

- Tourists gain multiple emotional benefits (ambience, experience, fun, adventure, contacts with other guests, etc.)

- The changes in potential tourist needs are perceivable.

The growth of standard of living has brought extra available money, but less free time, which are two basic preconditions for participation in tourism. As the answer to the fast tempo of modern urban life style, there is a growing need for intact, unpolluted areas. Personal safety becomes one of the crucial criteria in reaching the final decision, accompanied with the concern for personal health (wellness, fitness).

\section{References}

Assael, H. 1995. Consumer Behavior and Marketing Action, South-Western Publishing College, Cincinnati, 1-224.

Blackwel, R., Engel, J. 2005. Consumer Behavior, eight edition, The Dryden Press, International Edition, Oxford, pp. 1832.

Hadžić, O. 1989. Numeričke i statističke metode u obradi eksperimentalnih podataka, PMF, N. Sad, pp. 1-247.

Maričić, B. 2002. Ponašanje potrošača, Savremena administracija, Beograd. pp. 1595.

Mowen, J., C., Kotler, P. 20oo. Marketing Managament, Prentice Hall Inter., Inc, Upper Saddle River, pp. 1-237.

Pavluska, V., - www.gaia.jpte.hu/hallgatok/Fogzmag_files/slideooor.htm

Peters, J., P., Olson, J., C. 1999. Consumer Behavior and Marketing Strategy, Irwin, McGraw Hill, Singapore, pp. 1-162.

Schiffman, L., G.., Kanuk, L., L. 200o. Consumer Behavior, seventh edition, Prentice-Hall, New Jersey, pp. 1-469. 